\title{
BANCO DE DADOS DO ACERVO MAC USP: SALVAGUARDA, GERENCIAMENTO E APOIO À PESQUISA
}

\author{
Maria Cristina Cabral \\ Especialista em Documentação Museológica do \\ Museu de Arte Contemporânea da Universidade de São Paulo
}

Implantada em 1983, com base no primeiro regimento dos museus da Universidade de São Paulo, a Seção de Catalogação/Documentação do Museu de Arte Contemporânea da USP tem como principal atribuição a salvaguarda material e histórica do Acervo. Sua equipe é responsável pela catalogação das obras e pela organização da documentação de incorporação, pela elaboração de registros que preservem a história dessa Coleção, pela organização e gerenciamento de suas reservas técnicas e pela difusão das informações processadas.

Para otimizar o trabalho de salvaguarda, gerenciamento e difusão dessa Coleção de Arte Moderna e Contemporânea, utilizamos um Banco de Dados especialmente desenvolvido de modo a orientar o bom cumprimento de diversas tarefas do staff dedicado ao Acervo. A rapidez com que recuperamos os dados e o volume de informação agregada atestam, hoje, sua importância em nossas atividades rotineiras, sobretudo no atendimento a pesquisadores que não residem em São Paulo e podem receber listagens geradas através do sistema e transmitidas eletronicamente.

A estrutura de funcionamento do Banco de Dados do Acervo MAC USP foi elaborada de modo a atender três grupos de público: o catalogador, que utiliza o sistema como ferramenta de desenvolvimento do próprio trabalho; o público interno, que se beneficia principalmente das tabelas de gerenciamento de Acervo, e o público externo, para o qual desenvolvemos listagens de apoio à pesquisa baseadas em necessidades específicas, comunicadas previamente pelo pesquisador.

A utilização da informática como ferramenta de apoio à catalogação do Acervo MAC USP data de meados de 1986, quando recebemos da Reitoria nosso primeiro microcomputador para informatização do Acervo. Na época, por acervo informatizado entendia-se a digitação dos principais dados catalográficos em fichas eletrônicas com o objetivo de se produzir listagens de apoio à pesquisa e ao staff do Museu. Com o aplicativo dbase III e a contratação temporária de um programador, a Seção de Catalogação/Documentação do MAC iniciou sua experiência como usuário de informática. 
Passados dois anos da experiência inicial, já não nos contentávamos em ser simples usuários; precisávamos galgar outro patamar, o que fizemos através da elaboração e implantação de uma estrutura mais abrangente para o atual banco de dados. Infelizmente, por limitação do aplicativo e do hardware, não pudemos avançar, neste período, para a estrutura almejada, mas cada pequeno passo era uma motivação para continuarmos idealizando outro estágio no desenvolvimento e utilização dessa ferramenta.

No início dos anos 90, elaboramos um projeto de implantação de um sistema informatizado para o Acervo, que seria disponibilizado em rede interna. Por falta de recursos, este projeto nunca foi implantado; no entanto, as idéias esboçadas ali serviram para traçar outra estratégia de crescimento: poderíamos avançar aos poucos se identificássemos, na grande estrutura, cada núcleo da relação de interdependência. Também neste período, fizemos a migração automática das informações catalográficas contidas no banco de dados para o arquivo de composição eletrônica dos fotolitos do Catálogo Geral de Obras do Acervo MAC USP, publicado em 1992.

Seguindo a idéia de desenvolvimento por núcleos de informação, em 1994, quando a Seção de Catalogação conseguiu um equipamento melhor, uma versão mais avançada do aplicativo de banco de dados e a dedicação temporária de um analista de sistemas, introduzimos os primeiros campos de gerenciamento do Acervo: alguns deles controlavam a localização específica de cada peça nas reservas técnicas e seus respectivos deslocamentos; outros controlavam seus compromissos, ou seja, se as obras estavam reservadas para alguma exposição no próprio MAC, ou em outra instituição. Além disso, porque finalmente tínhamos espaço no disco rígido, implantamos a tabela de exposições, o que ampliava o controle dos dados históricos do Acervo, subsidiando, portanto, mais pesquisas automáticas relacionadas a ele.

Em 1997, com a aprovação, pela FAPESP, de um projeto de infraestrutura, a Seção de Catalogação/Documentação pôde adquirir um microcomputador de última geração. Nesta nova etapa, passamos a utilizar o Access 2, que era muito mais ágil que o Dbase e nos concentramos em sofisticar aquele que seria o principal ponto de uma futura rede interna do sistema, ou seja, as tabelas de salvaguarda e gerenciamento controladas pelo documentalista de Acervo. Além disso, como já tínhamos 10 anos de experiência em produção de listas de apoio, passamos a automatizar as consultas mais solicitadas pelo staff de Acervo e por pesquisadores, formatando relatórios específicos para cada grupo. Iniciou-se, também, o 
banco de imagens do Acervo, que era vinculado ao banco de dados. Embora trabalhássemos com uma maior quantidade de informações, ainda não tínhamos o tão almejado sistema por falta de recursos humanos especializados.

Em 2001, por meio de outro projeto de infra-estrutura apoiado pela FAPESP, conseguimos mais um microcomputador e passamos a trabalhar com o Access 2000, que continha muito mais recursos que a versão anterior. Neste período, iniciamos o estudo dos protocolos de segurança para o funcionamento em rede; além disso, implantamos tabelas, consultas, formulários e relatórios mais sofisticados para o controle e gerenciamento do Acervo. Documentos como esquemas de montagem de instalações e obras de estrutura múltipla começaram a ser digitalizados e vinculados ao sistema especialmente para atender às necessidades operacionais da equipe de Museografia. Foi um período de intenso desenvolvimento da estrutura do sistema e de testes de disponibilização em rede. $\mathrm{O}$ atendimento a pesquisadores também foi intensificado, pois dispúnhamos de um volume maior de informação cadastrada.

O verdadeiro salto qualitativo veio em 2003, quando o servidor passou por um upgrade. Isso nos possibilitou implantar o primeiro ponto de rede fora da Seção de Catalogação/Documentação, introduzindo ao sistema 2 novos usuários: a Seção de Empréstimos e Reproduções do Acervo e a Secretaria da Divisão Técnico-científica de Acervo. Com isso, a Seção de Catalogação/Documentação descentralizou a alimentação e utilização do Banco de Dados do Acervo. O restante do staff do MAC, que ainda não pode acessar o sistema, passou a contar com listas criadas automaticamente a partir do Banco de Dados do Acervo e disponibilizadas em rede interna (arquivos txt e pdf). Assim, cada vez que cadastramos um projeto de exposição no sistema, podemos gerar automaticamente listagens específicas para cada área da cadeia de produção: Curadoria, Laboratórios de Conservação e Restauro, Museografia, Comunicação Visual, Setor de Montagem, Assessoria de Imprensa e Divulgação.

Nosso próximo passo será disponibilizar na web formulários de consulta aos dados catalográficos de todo o Acervo, otimizando o acesso de pesquisadores a essas informações. Também pretendemos inserir novos usuários de nosso staff no sistema. De acordo com nosso planejamento, os próximos serão os especialistas em conservação e restauro, que poderão contar com a automatização de suas fichas de conservação e de tratamento. Estamos elaborando, ainda, tabelas de metadados para agilizar a busca de documentos e de arquivos eletrônicos de imagens. 
Nosso objetivo é fazer com que o sistema atenda, de forma cada vez mais eficiente, seus três grupos de público, chegando mesmo a antecipar suas necessidades e a interferir positivamente no desenvolvimento das rotinas internas.
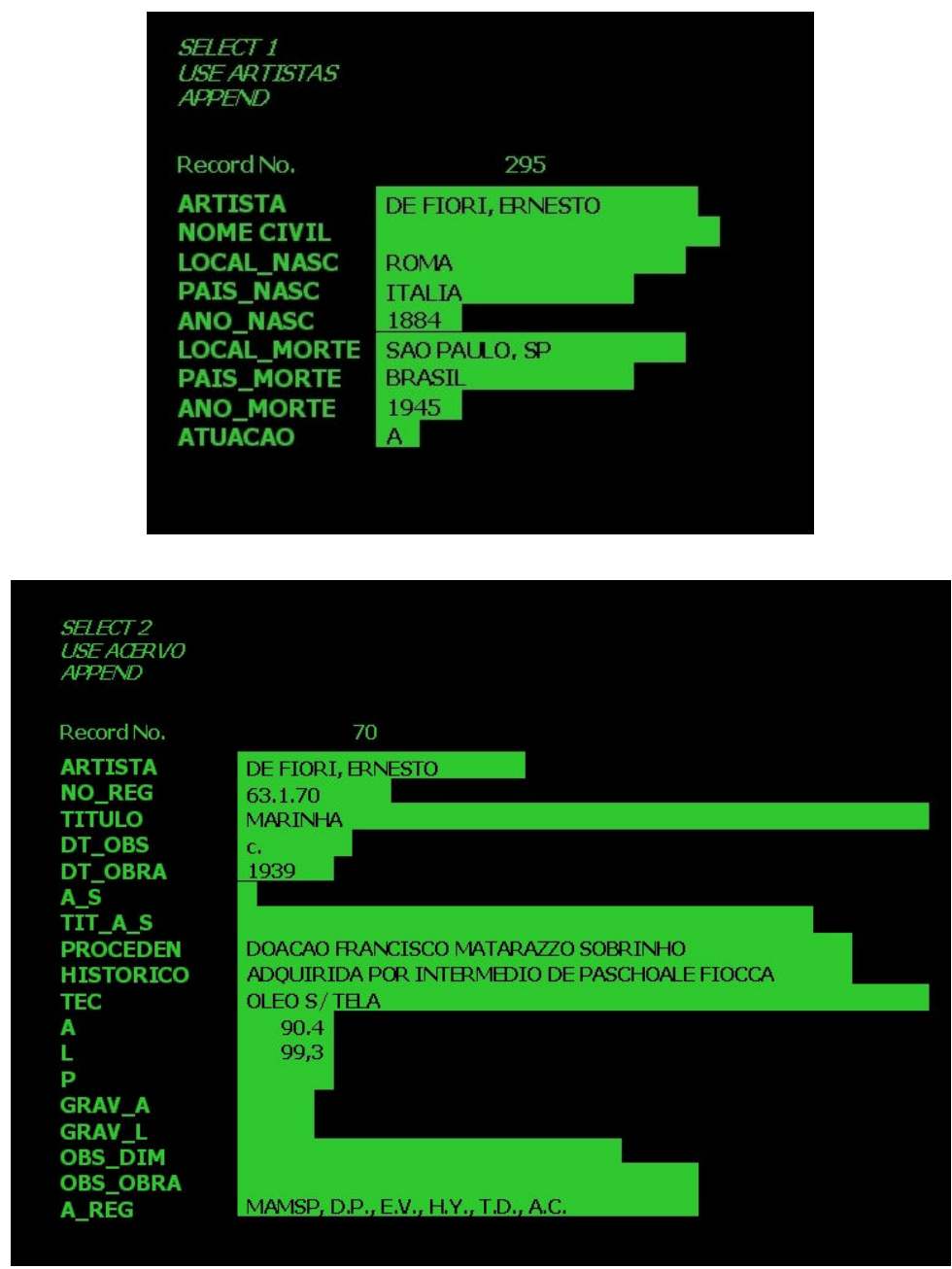

Layout dos arquivos do Banco de Dados do Acervo MAC USP em 1986 


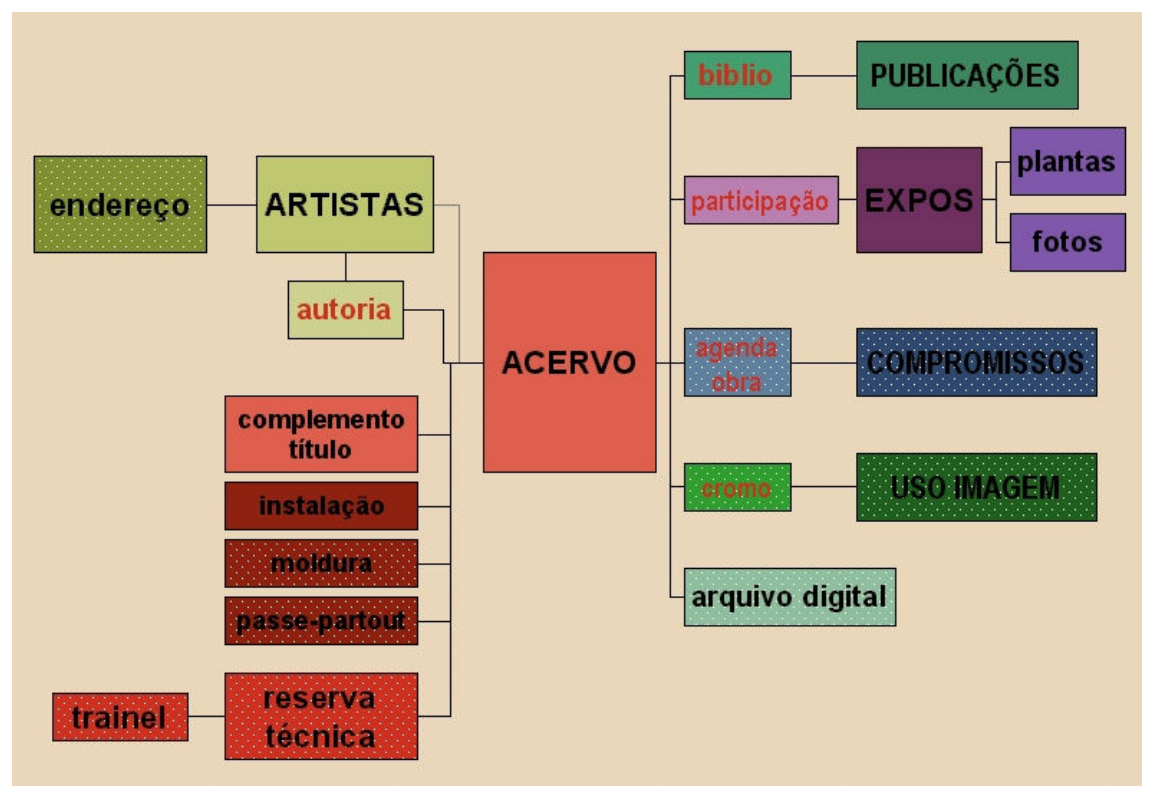

Atual estrutura de relacionamento das tabelas do Banco de Dados do Acervo MAC USP 